\title{
DESIGNING COMPOSITE BEAMS WITH PRECAST HOLLOWCORE SLABS TO EUROCODE 4
}

\author{
D. Lam \\ Senior Lecturer, School of Civil Engineering, University of Leeds, Leeds, LS29JT, UK \\ (Corresponding author: E-mail: d.lam@leeds.ac.uk)
}

Received: 15 November 2005; Revised: 26 January 2007; Accepted: 1 February 2007

\begin{abstract}
The design of multi-storey buildings in the UK, in the past, considered steel and concrete structures in isolation. Today, designers utilize the combined properties of steel and concrete in the form of composite or hybrid structures as a more attractive efficient alternative. Designers of steel structures acknowledge that the presence of concrete slabs may be designed compositely with steel beams in order to increase both flexural strength and stiffness at virtually no extra cost, except for the headed shear studs. The use of composite construction with precast hollowcore slabs has become one of the most popular construction methods in the UK. Currently, design of composite construction is covered by BS5950, Part 3, but will soon be replaced by the new European Standard, Eurocode 4. However, design of composite construction with precast hollowcore slabs is currently outside the provisions of this new code. In this paper, an overview of the Eurocode 4 structure and its contents are first presented and some of the particular issues that affect this new form of construction will be given. Design guidance using the Eurocode methodology will also be presented.
\end{abstract}

Keywords: Eurocode 4; composite design; precast; hollowcore; steel; connection design; moment capacity; effective length

\section{INTRODUCTION}

The environmental impacts of human activities have risen to the forefront of international concern in recent years. A mixture of legislation, public opinion and social responsibility has driven construction industries throughout the world to reduce pollution and waste. Among all sectors of economic activity, the buildings and construction sector has by far the greatest environmental impact in terms of resource consumption and offers enormous scope for improvement. As the construction industry demands for rapid construction with reduction in cost and environmental impacts, composite construction, especially those without major onsite concreting, has become very popular among the designers and engineers in the UK.

Use of composite elements in the form of beams, and slabs are already common in the UK. The application is currently supported by the British Standard, BS5950, Part 3 [1] but will soon be replaced by a new standard harmonized across Europe, EN1994 - Eurocode 4 [2]. This code formed part of a complete set of design codes developed in the Eurocode programme by the European Standards Organization (CEN) initiated by the Commission of the European Communities. The programme aims to harmonize all the code of practices across the whole European communities, it also aims to harmonize between different construction materials, e.g. steel, concrete, masonry etc, and construction methods to achieve full consistency and compatibility in terms of loading, safety factors so that a comparable safety levels can be obtained.

In 1975, the Commission of the European Community decided on an action programme in the field of construction, based on article 95 of the Treaty. The objective of the programme was the elimination of technical obstacles to trade and the harmonization of technical specifications. Within the programme, the Commission took the initiative to establish a set of harmonized technical rules for the design of construction works which, in a first stage, would serve as an alternative to the national rules in force in the Member States and, ultimately, would replace them. 
The National Standards implementing Eurocodes will comprise the full text of the Eurocode (including any annexes), as published by CEN, which may be preceded by a National title page and National foreword, and may be followed by a National annex. The National annex may only contain information on those parameters, which are left open in the Eurocode for national choice, known as Nationally Determined Parameters, to be used for the design of buildings and civil engineering works to be constructed in the country concerned, i.e.:

- values and/or classes where alternatives are given in the Eurocode,

- values to be used where a symbol only is given in the Eurocode,

- country specific data (geographical, climatic, etc.), e.g. snow map,

- the procedure to be used where alternative procedures are given in the Eurocode.

It may also contain

- decisions on the use of informative annexes, and

- references to non-contradictory complementary information to assist the user to apply the Eurocode.

\subsection{Eurocode $4-$ EN1994}

Eurocode 4 was first drafted in 1985 and published in 1992 as ENV1994 and accompanied by the National Application Documents (NAD's). It is intended that the Eurocode together with its NAD may be used optional to the National Standard. The difficulty associated with the Eurocode 4 document is that the code must be consistent on one hand with the material independent parts of EN1990 [3] \& EN1991 [4] and on the other hand, consistent with the Eurocode 2 [5] for concrete structures and Eurocode 3 [6] for the steel structures. For this consistency, CEN insisted that information is not repeated in each code but referring across the codes. Therefore, EN1994 must be used in conjunction with all the related Eurocodes. For this reason, it is difficult to design using the Eurocode 4 until all the other Eurocodes are ready. Figure 1 shows the relationship of the EN1994 with the other Eurocodes.

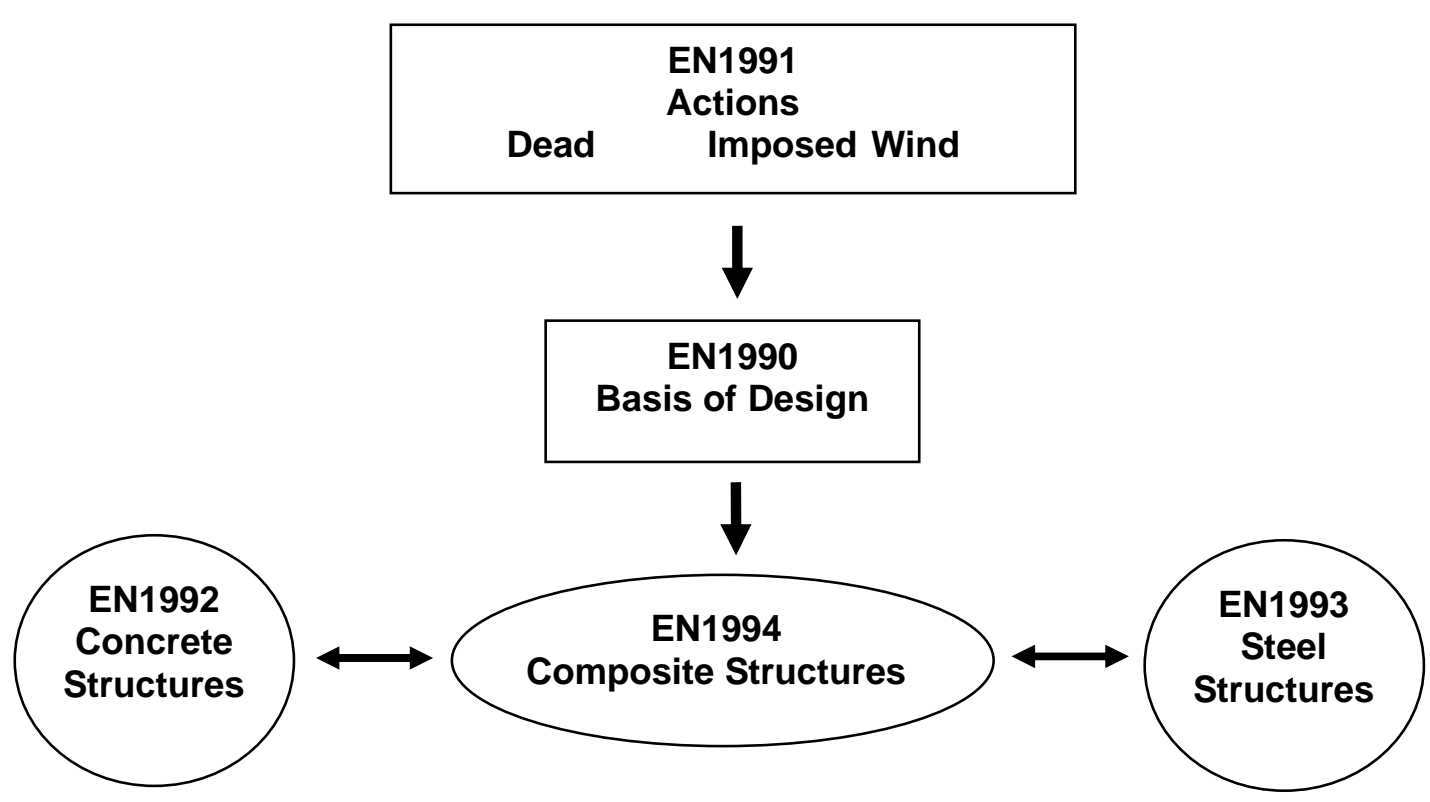

Figure 1. Designing Composite Structures Using the Eurocodes 
As shown in Figure 1, for the design of the composite structures, material properties related to concrete part of the structures must be referred to the EN1992, i.e. grade, modulus of elasticity and strength of the concrete, while the material properties related to the steel part of the composite structures must be referred to the EN1993, for example, steel grade, yield strength and modulus of elasticity. In addition, design rules such as effective width, classification of cross sections, etc. will need to be consistent across all the related codes.

Part 1-1 of Eurocode 4 gives a general basis for the design of composite structures together with specific rules for buildings. The following subjects are dealt with in Part 1-1:

Section 1: General

Section 2: Basis of design

Section 3: Materials

Section 4: Durability

Section 5: Structural analysis

Section 6: Ultimate limit states

Section 7: Serviceability limit states

Section 8: Composite joints in frames for buildings

Section 9: Composite slabs with profiled steel sheeting for buildings

Annex A: Stiffness of joint components in buildings.

Annex B: Standard tests.

Annex C: Shrinkage of concrete for composite structures for buildings.

As discussed earlier on, composite construction with precast hollowcore slabs is currently outside the provisions of the current EN1994. This paper discusses some of the particular issues that affect this form of construction, and presents a design guidance using the Eurocode methodology.

\section{COMPOSITE CONSTRUCTION WITH PRECAST HOLLOWCORE SLABS}

In composite construction, the most important piece of information relevant to composite beam design is the shear connectors load - slip capacity. This load-slip characteristic of the shear connectors have mainly been obtained from the push off tests. Although the push off test cannot exactly simulate the actual conditions occurring in a composite beam, it does enable the behaviour of different types and sizes of shear connectors to be compared provided the test is standardized. The standard push off test for shear connectors is currently covered by Annex B in the EN1994-1-1and as shown in Figure 2.

\subsection{A. Basis of Design for the Shear Connectors}

The basis principles for the design of shear connector are as follow:

(1) Shear connectors and transverse reinforcement shall be provided to transmit the longitudinal shear force between the concrete and the structural steel element, ignoring the effect of natural bond between the two.

(2) Shear connectors shall have sufficient deformation capacity to justify any inelastic redistribution of shear assumed in design.

(3) Ductile connectors are those with sufficient deformation capacity to justify the assumption of ideal plastic behaviour of the shear connection in the structure considered.

(4) A connector may be taken as ductile if the characteristic slip capacity $\delta_{\mathrm{uk}}$ is at least $6 \mathrm{~mm}$. An evaluation of $\delta_{\mathrm{uk}}$ is given in Annex B of the EN1994-1-1.

(5) Shear connectors shall be capable of preventing separation of the concrete element from the steel element, except where separation is prevented by other means. 
(6) To prevent separation of the slab, shear connectors should be designed to resist a nominal ultimate tensile force, perpendicular to the plane of the steel flange, of at least 0.1 times the design ultimate shear resistance of the connectors. If found necessary, they should be supplemented by anchoring devices.

(7) Headed stud shear connectors may be assumed to provide sufficient resistance to uplift, unless the shear connection is subjected to direct tension.

(8) Longitudinal shear failure and splitting of the concrete slab due to concentrated forces applied by the connectors shall be prevented.

As the current standard push off test is not suitable for composite precast hollowcore construction, a new standardize push off test is needed to fill the gap in the Eurocode 4.
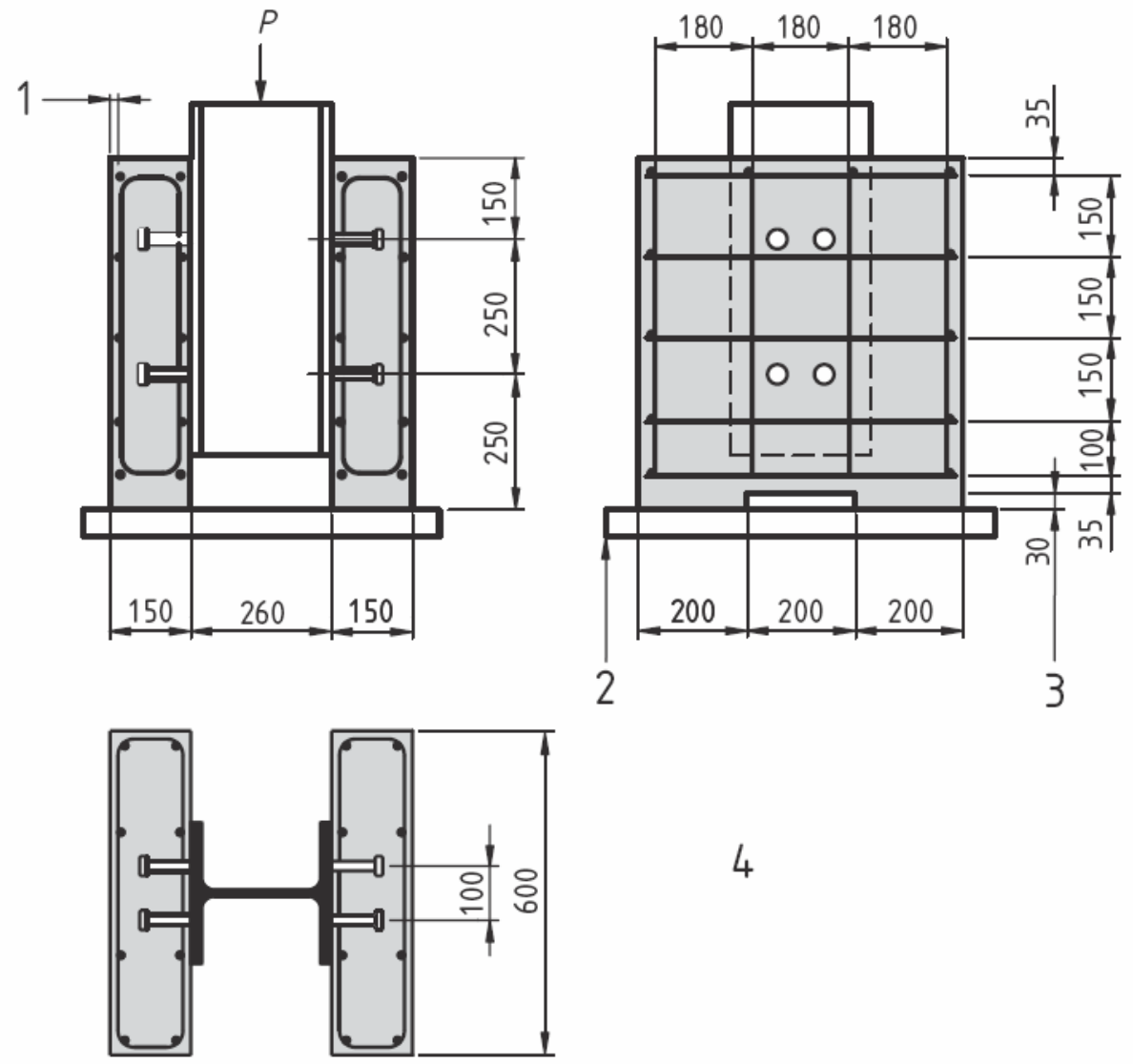

Key

1 Cover $15 \mathrm{~mm}$

2 Bedded in mortar or gypsum

3 Recess optional

4 Reinforcement: ribbed bars $\phi 10 \mathrm{~mm}$ resulting in a high bond with $450 \leq \mathrm{f}_{\mathrm{sk}} \leq 550 \mathrm{~N} / \mathrm{mm}^{2}$

Steel section: HE 260B or $254 \times 254 \times 89 \mathrm{~kg} / \mathrm{m}$ UC

Figure 2. Test Specimen for Standard Push Off Test

\subsubsection{New push off test for hollowcore slabs}

A new horizontal push off test arrangement is proposed by Lam [7] as shown in Figure 3. The test specimens each consisted of four $600 \mathrm{~mm}$ wide $\mathrm{x} 800 \mathrm{~mm}$ long prestressed hollowcore units connected to a $254 \times 254 \times 73$ UC with a single row of 6 pre-welded headed studs at $150 \mathrm{~mm}$ centres. Cores of $500 \mathrm{~mm}$ long were left open to allow placement of the transverse reinforcement. 
The $600 \mathrm{~mm}$ slab width was chosen instead of the common $1200 \mathrm{~mm}$ width so that the effect of the transverse joint could be observed. The in-situ concrete infill was cast horizontally and tested when the required design strength is reached. Horizontal load was applied to the specimen by two hydraulic jacks bracketed in parallel on to the steel beam and working against the slab via spreader beams.

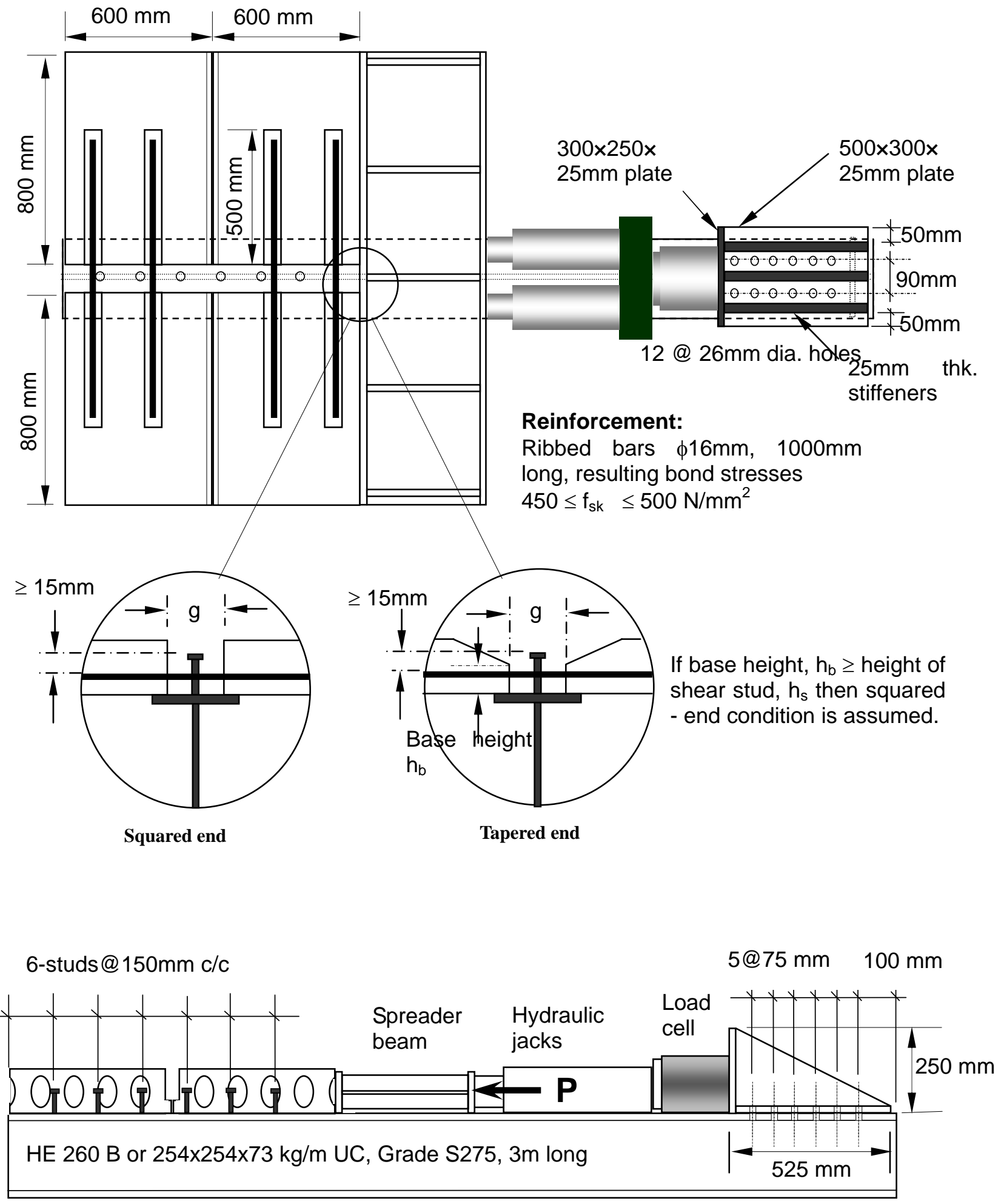

Figure 3. General Arrangement for Horizontal Push Off Test 
Longitudinal slip is measured by LVDTs at the end of the slabs until the load has dropped to $20 \%$ below the maximum load reached. This enables the load and slip capacity to be determined. Because the slab is cast and loaded in the horizontal position as it would be in practice, the construction difficulties using this standard push off test for hollowcore slabs (HCS) and the inherent possibility in the standard vertical push off test where the weaker concrete slab failing first are eliminated.

Over 100 full-scale push off tests were carried out with different parameters (i.e. studs sizes, hollowcore slabs thickness, end profile, in-situ infill concrete strength and transverse reinforcement) in accordance to the new push off test procedure to determine the shear capacity of the headed stud. Based on the push off test results, equations for determining the shear capacity of the headed studs in precast hollowcore slabs showed in Figure 4 together with the new push off test procedures have been submitted to the EC4 committee for consideration.

\subsubsection{Headed Stud connectors used with precast hollowcore slabs}

The design shear resistance of an automatically welded headed stud with a normal weld collar, should be determined from

$$
P_{R D}=0.8 f_{u}\left(\pi d^{2} / 4\right) / \gamma_{v}
$$

or

$$
P_{R D}=0.29 \alpha \beta \varepsilon d^{2} \sqrt{\omega f_{c p} E_{c p}} / \gamma_{v}
$$

whichever is smaller,

where $\quad d=\quad$ is the diameter of the shank of the stud;

$f_{u}=\quad$ is the specified ultimate tensile strength of the material of the stud but not greater than $500 \mathrm{~N} / \mathrm{mm}^{2}$;

$\alpha=\quad a$ factor which takes into account the gap width $\mathrm{g}(\mathrm{mm})$ and is given as $0.5(g / 70+1) \leq 1.0$, and $g \geq 30 \mathrm{~mm}$;

$\beta=\quad a$ factor which takes into account the diameter $\phi$ of transverse high tensile tie steel (grade 460$)$ and is given by $0.5(\phi / 20+1) \leq 1.0$, and $\phi \geq$ $8 \mathrm{~mm}$;

$\omega=\quad$ transverse joint factor $=0.5(w / 600+1), w=$ width of hcu

$f_{c p}=\quad$ average concrete cylinder strength $=0.8 \times$ average cube strength of the in-situ and precast concrete;

$E_{c p}=\quad$ average value of elastic modulus of the in-situ and precast concrete.

The partial safety factor $\gamma_{\mathrm{v}}$ should be taken as 1.25 for the ultimate limit state.

Figure 4. Proposed Equations for the Headed Shear Connection with Precast Hollowcore Slabs 


\subsubsection{Effective width of flanges for shear lag}

In composite design, allowance need to be made for the flexibility of the concrete flanges affected by in-plane shear (shear lag), it can be done either by means of rigorous analysis, or by using an effective width of the concrete flange. In EC4, the effective width of concrete flanges is determined in accordance with Figure 5. When elastic global analysis is used, a constant effective width may be assumed over the whole of each span. This value may be taken as the value $b_{\text {eff, } 1}$ at mid-span for a span supported at both ends, or the value $b_{\text {eff,2 }}$ at the support for a cantilever.

At mid-span or an internal support, the total effective width $b_{\text {eff, }}$ see Figure 5, may be determined as:

$b_{\text {eff }}=b_{0}+\sum b_{\mathrm{ei}}$

where:

$b_{0} \quad$ is the distance between the centres of the outstand shear connectors;

$b_{e i} \quad$ is the value of the effective width of the concrete flange on each side of the web and taken as $L e / 8$ but not greater than the geometric width $b_{i}$. The value $b i$ should be taken as the distance from the outstand shear connector to a point mid-way between adjacent webs, measured at mid-depth of the concrete flange, except that at a free edge $b i$ is the distance to the free edge.

The effective width at an end support may be determined as:

$b_{\text {eff }}=b_{0}+\sum \beta_{i} b_{e i}$

with

$\beta_{i}=\left(0,55+0,025 L_{e} / b_{e i}\right) \leq 1,0$

where:

$b_{e i} \quad$ is the effective width of the end span at mid-span and Le is the equivalent span of the end span according to Figure 5.

\subsubsection{Effective width of hollowcore slabs}

The calculation for the effective width of the hollowcore slabs is more complicated than the Eurocode method due to the presence of the hollow cores (voids) within the concrete slabs. Figure 6 shows the section of the composite beam with precast hollowcore slabs. From the results of the experimental work and FE analyses carried out by Lam et al. [8, 9] and Murad \& Lam [10], it showed that the effective width for this form of construction is affected by the in-situ concrete infill, the precast hollowcore slabs and the transverse reinforcement. Based on the research work, an empirical equation for calculating effective width for the hollowcore slabs is proposed:

$b_{\text {eff }}=\frac{\sqrt{f_{c k, i}}}{35} \times \frac{32 \phi_{\mathrm{r}}}{500} \times \frac{f_{\text {sd }}}{460} \times 1000+2.5 \mathrm{~g}$ 


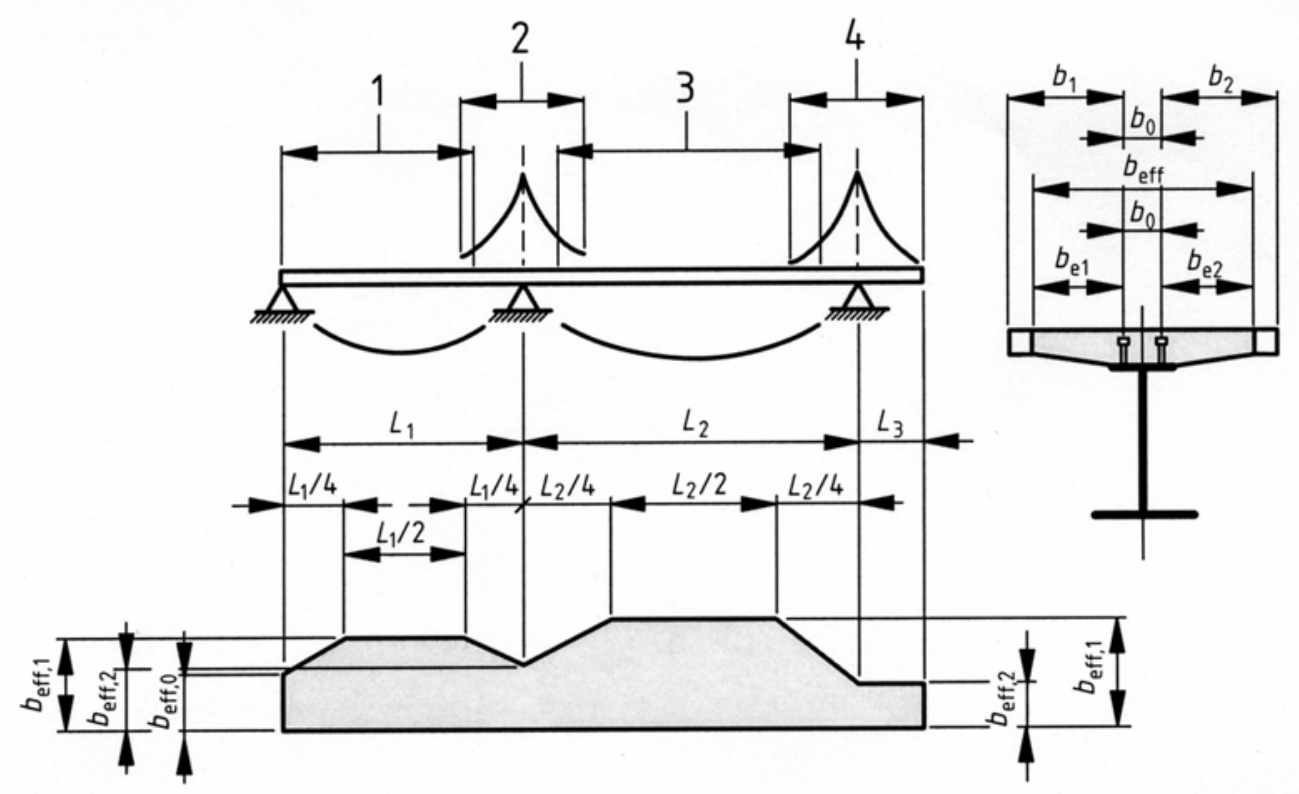

Key

$1 \quad L_{\mathrm{e}}=0,85 L_{1}$ for $b_{\text {eff, } 1}$

$2 L_{\mathrm{e}}=0,25\left(L_{1}+L_{2}\right)$ for $b_{\mathrm{eff}, 2}$

$3 L_{\mathrm{e}}=0,70 L_{2}$ for $b_{\mathrm{eff}, 1}$

$4 \quad L_{\mathrm{e}}=2 L_{3}$ for $b_{\mathrm{eff}, 2}$

Figure 5. Equivalent Spans for Effective Width of Concrete Flange

where

$f_{c k, i}$ is the in-situ infill concrete strength in $\mathrm{N} / \mathrm{mm}^{2}$.

$\phi_{r}$ is the diameter of the transverse reinforcement in $\mathrm{mm}$.

$f_{s d}$ is the characteristic strength of the transverse reinforcement in $\mathrm{N} / \mathrm{mm}^{2}$.

$g$ is the gap between the precast units

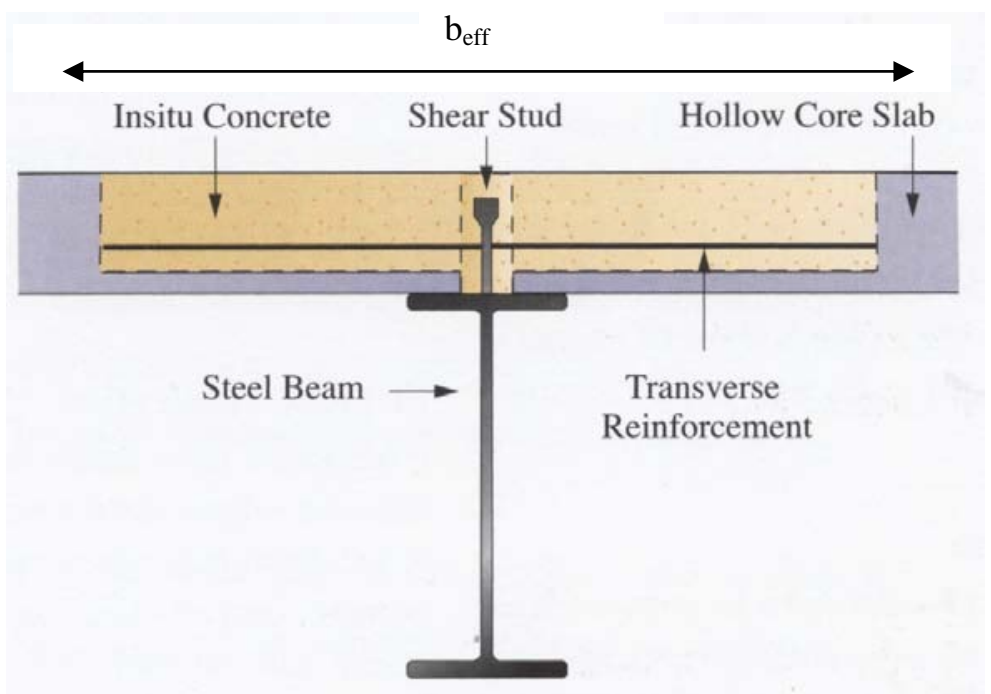

Figure 6. Effective Width of Hollowcore Slabs 


\subsection{Moment Resistance of the Composite Beams}

The bending resistance of the composite beams can be determined by rigid-plastic theory only where the effective composite cross-section is in Class 1 or Class 2. Otherwise, elastic analysis and non-linear theory for bending resistance may be applied to cross-sections of any class. It is assumed that the composite cross-section remains plane if the shear connection and the transverse reinforcement are designed in accordance with Cl.6.6, to distribute the design longitudinal shear force. The tensile strength of concrete shall be neglected.

The following assumptions should be made in the calculation of $\mathrm{M}_{\mathrm{pl}, \mathrm{Rd}}$ :

a) there is full interaction between structural steel, reinforcement, and concrete;

b) the effective area of the structural steel member is stressed to its design yield strength $f_{y d}$ in tension or compression;

c) the effective areas of longitudinal reinforcement in tension and in compression are stressed to their design yield strength $f_{\text {sd }}$ in tension or compression. Alternatively, reinforcement in compression in a concrete slab may be neglected;

d) the effective area of concrete in compression resists a stress of $0.85 \mathrm{f}_{\mathrm{cd}}$ constant over the whole depth between the plastic neutral axis and the most compressed fibre of the concrete, where $\mathrm{f}_{\mathrm{cd}}$ is the design cylinder compressive strength of concrete.

Typical plastic stress distributions are shown in Figure 7.
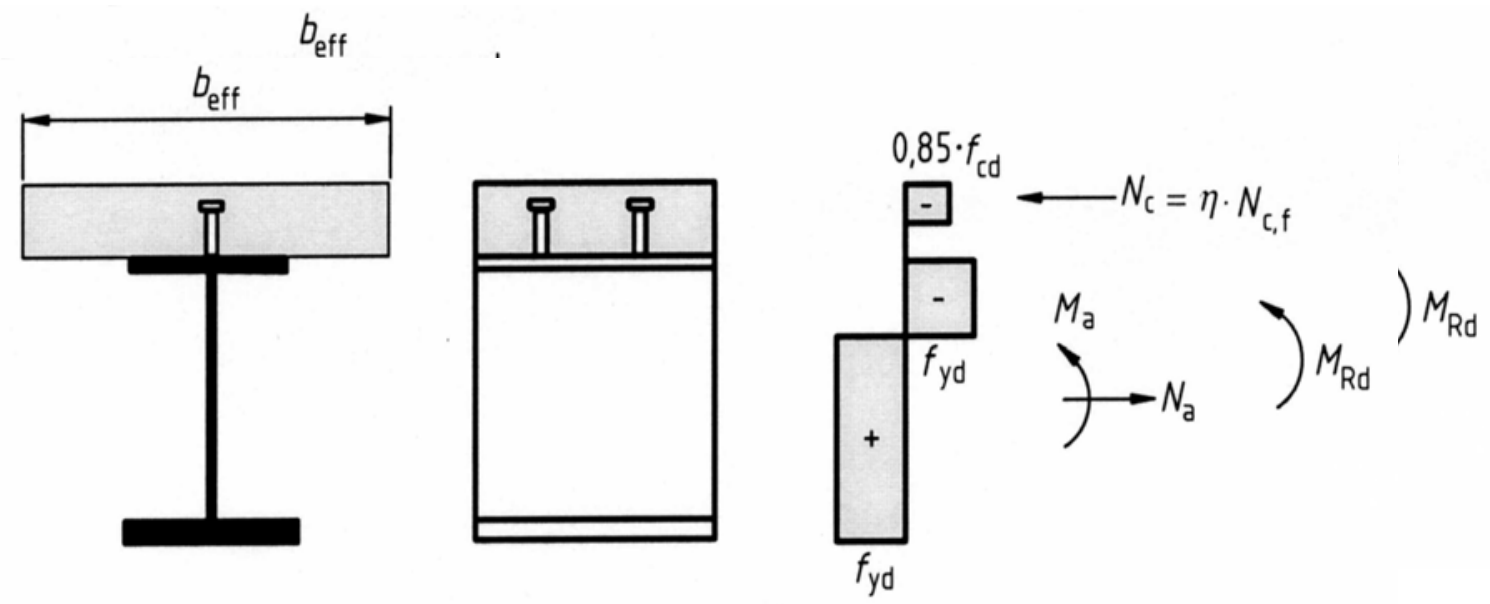

Figure 7. Plastic Stress Distributions under Sagging Bending for Partial Shear Connection

\subsubsection{Moment resistance of composite beams with precast hollowcore slabs}

For composite beams with precast hollowcore slabs, similar rigid plastic theory is applied. The only limitation applied for this form of construction is that the plastic neutral axis is below the steel concrete interface. Figure 8 shows the plastic stress distributions under sagging bending with full shear connection. 


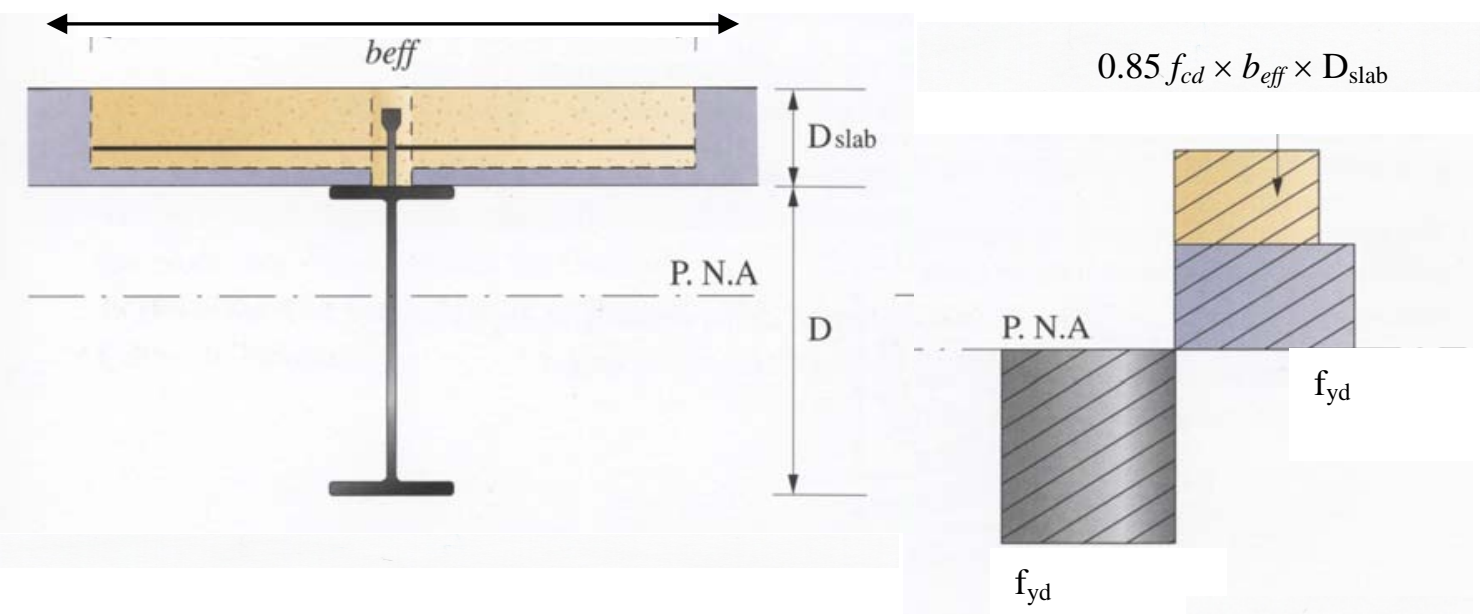

Figure 8. Plastic Stress Distributions under Sagging Bending for Full Shear Connection

The moment resistance of the composite sections where neutral axis is within the web is given below:

$M_{p l, R d}=M_{p l, a}+N_{c, f} \frac{\left(D+D_{s l a b}\right)}{2}-\frac{D}{4}\left(\frac{N_{c, f}^{2}}{N_{a, w}}\right)$

where

$M_{p l, a} \quad$ is the moment resistance of the steel section

$D \quad$ is the steel section depth

$D_{\text {slab }} \quad$ is the concrete slab depth

$N_{c, f} \quad$ is the compressive resistance of the concrete flange

$N_{a, w} \quad$ is the resistance of the web of the steel section

\section{$2.3 \quad$ D. Composite Joints}

In steel braced frame structures, the most economical solution is to use nominal pinned joints. However, since longitudinal reinforcement is required over the supports; in order to limit cracking in providing additional tying against disproportional collapse, it will be technically and economically advantages to design the joints as composite joints in which the longitudinal reinforcement will contribute to the resistance and the stiffness of the joint. Composite joints in building are covered in section 8 of Eurocode 4 and the section is consistent with the EN1993-1-8 [11]. The design of moment capacity of these joints are based on the so-called 'component method'. Figure 9 shows the example of the composite joints. With regard to the rotation capacity of these joints, the influence of cracking of concrete, tension stiffening and deformation of the shear connection should be considered in determining the rotation capacity. The rotation capacity of a composite joint may be demonstrated by experimental evidence. Alternatively, calculation methods may be used, provided that they are supported by tests. In general, composite joints with rotation capacity in excess of $30 \mathrm{mRad}$ are acceptable for design purposes. 


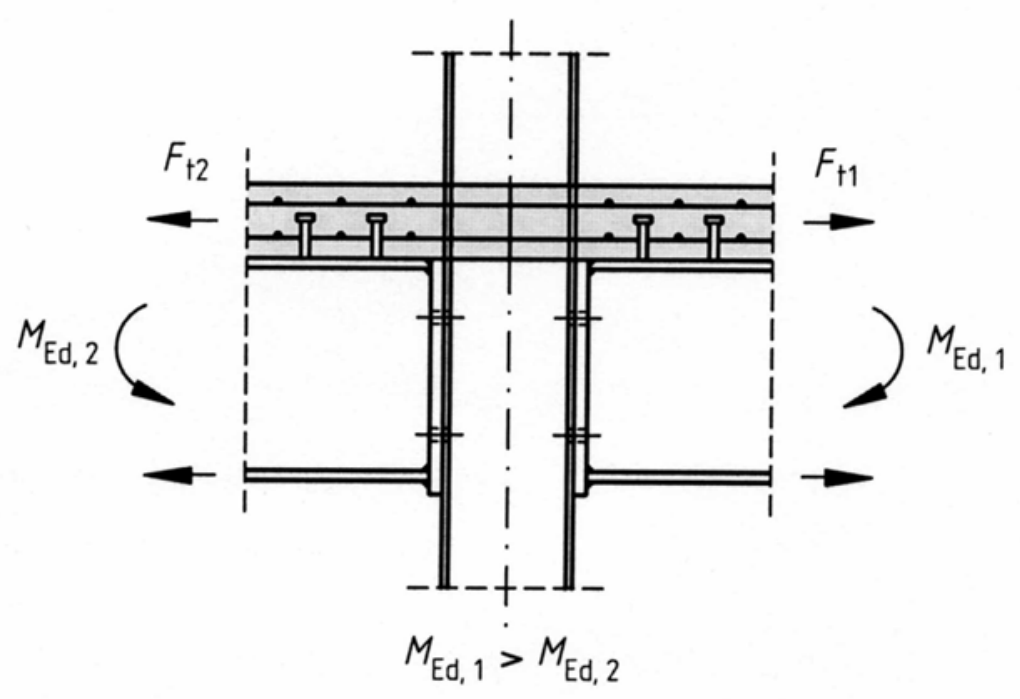

Figure 9. Composite Joint

\subsubsection{Composite joints with precast hollowcore slabs}

Figure 10 shows the force diagram and component of the composite joints. Equation (6) based on the component method are proposed to predict the rotation capacity, $\phi_{\mathrm{u}}$ for this form of composite joints. From the strain profile of the longitudinal reinforcing bar taken from the tests data by Lam \& $\mathrm{Fu}$ [12], it shows that the steel bar yielded only in the region between the column centre line and the second shear stud, the strain in the other part of the steel bar is small and remained elastic. Therefore, the elongation zone of the longitudinal reinforcement, $\Delta L$ can be taken as between the centre line of the column and the position of the second stud. Hence, it can assumed that the length for calculating the elongation to be $\mathrm{p}_{1}+\mathrm{p}_{2}+\mathrm{D} / 2$, where $\mathrm{p}_{1}$ is the distance between the column face and the centre line of the first stud; $\mathrm{p}_{2}$ is the distance between the centre line of the first stud and the second stud and $\mathrm{D}$ is the depth of the column.

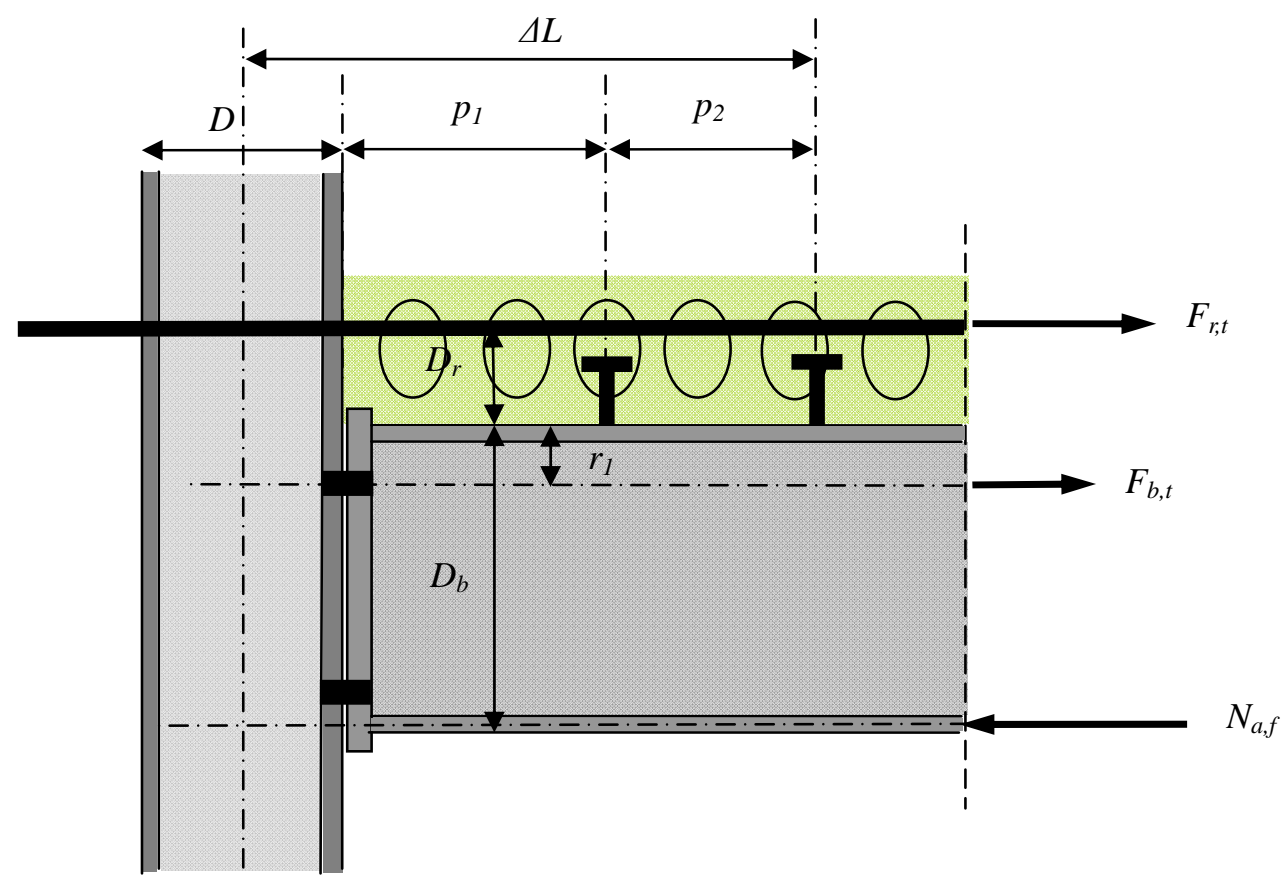

Figure 10. Force Diagram and the Components of the Composite Joint 
$\phi_{u}=\frac{\Delta L}{D_{b}+D_{r}}+\frac{\text { Slip }}{D_{b}}$

where $\Delta L=\varepsilon_{\text {sh }}\left(p_{1}+p_{2}+\frac{D}{2}\right)$

For full shear connection, reinforcement strain, $\varepsilon_{\mathrm{sh}}$ is taken as the ultimate strain developed in the longitudinal reinforcement. It is because that for full shear connection, the longitudinal reinforcing bars can be developed into the strain hardening whereas for the partial shear connection, $\varepsilon_{\mathrm{sh}}$ is taken as the maximum strain developed in the longitudinal bar. For simplicity, it can be taken as the yield strain of the steel bars if enough shear studs are provided to enable yielding of the longitudinal bars.

The moment resistance of the composite joint, $M_{R d}$

For $N_{a, f} \geq F_{b, t}+F_{r, t}$

where,

$N_{a, f}=$ compressive resistance of the bottom flange of the steel beam,

$F_{r, t}=$ tensile strength of the longitudinal reinforcement,

$F_{b, t}=$ effective tensile resistance of the bolt group.

$M_{R d}=F_{r, t}\left(D_{b}+D_{r}-0.5 t_{f}\right)+F_{b, t}\left(D_{b}-r_{1}-0.5 t_{f}\right)$

where,

$D_{b}=$ the depth of the beam,

$r_{1}=$ the distance of the first row of bolts below the top of the beam,

$D_{r}=$ the distance of the reinforcement above the top of the beam,

$t_{f}=$ the flange thickness of the steel beam.

For $N_{a, f}<F_{b, t}+F_{r, t}$,

The neutral axis, $y_{c}=\frac{\left(F_{r, t}+F_{b, t}-N_{a, f}\right)}{t_{w} f_{y d}}$

where,

$t_{w}=$ the web thickness and

$f_{y d}=$ the design strength of steel section.

The moment resistance of the composite connection, $M_{R D}$

$M_{R D}=F_{r, t}\left(D_{b}+D_{r}-0.5 t_{f}\right)+F_{b, t}\left(D_{b}-r_{1}-0.5 t_{f}\right)-F_{w, t} \frac{y_{c}}{2}$

where $R_{w}=y_{c} t_{w} f_{y d}$

\section{CONCLUSIONS}

In this paper, an overview of the Eurocode structures and the contents of the Eurocode for composite construction, EN1994 are presented. In particular, technical details especially related to the design of the composite beams are discussed and compared with the treatment to the composite construction with precast hollowcore slabs. Design guidance for this form of construction using the 
Eurocode methodology is discussed and new equations and design method are proposed.

\section{ACKNOWLEDGEMENT}

The author would like to acknowledge the financial support from the International Precast Hollowcore Association (IPHA) and Overseas Research Scholarship (ORS), the support provided by Severfield - Revee Structures Ltd. for supplying the steel specimens and Bison Concrete Products Ltd. for supplying the precast hollowcore slabs. The skilled assistance provided by the technical staff in the School of Civil Engineering at University of Leeds is also appreciated.

\section{REFERENCES}

[1] BS5950, Part 3, Structural Use of Steelwork in Building - Design in Composite Construction, British Standards Institution, London, 1990.

[2] EN1994-1-1, Eurocode 4: Design of Composite Steel and Concrete Structures: Part 1.1: General rules and rules for buildings, British Standards Institution, London, 2004.

[3] EN1990, Eurocode - Basis of Structural Design, British Standards Institution, London, 2002.

[4] EN1991, Eurocode 1 - Actions on Structures, British Standards Institution, London, 2002.

[5] EN1992-1-1, Eurocode 2 - Design of Concrete Structures, British Standards Institution, London, 2004.

[6] EN1993-1-1, Eurocode 3 - Design of Steel Structures, British Standards Institution, London, 2005.

[7] Lam, D., “New Test for Shear Connectors in Composite Construction”, United Engineering Foundation Conference, Composite Construction in Steel and Concrete IV, Banff, Alberta, Canada, 2000, pp. 404-414.

[8] Lam, D., Elliott, K.S. and Nethercot, D.A., "Experiments on Composite Steel Beams with Precast Concrete Hollow Core Floor Slabs", Proceedings of the Institution of Civil Engineers: Structures and Buildings, 2000a, Vol. 140, pp. 127-138.

[9] Lam, D., Elliott, K.S. and Nethercot, D.A., "Parametric Study on Composite Steel Beams with Precast Concrete Hollow Core Floor Slabs”, Journal of Constructional Steel Research, 2000b, Vol. 54, No. 2, pp. 283-304.

[10] Murad, A. and Lam, D., "Experimental Study of Long Span Composite Beams with Precast Hollow-Core Slabs", Eurosteel, 4th European Conference on Steel and Composite Construction, Maastricht, 2005.

[11] EN1993-1-8, Eurocode 3 - Design of Steel Structures, Part 8: Design of Joints, British Standards Institution, London, 2005.

[12] Lam, D and Fu, F., "Behaviour of Composite Steel Beams with Precast Hollow Core Slabs in Hogging Moment Regions”, 4th International Conference on Advances in Steel Structures, Shanghai, China, 2005. 